\title{
Enhancing User Experience for Mobile Learning Using Augmented Reality and Learning Style
}

\author{
Apichaya Nimkoompai ${ }^{1}$ \\ Worapat Paireekreng ${ }^{2}$ \\ Suwannit Chareen Chit $^{3}$ \\ ${ }^{1,2}$ Dhurakij Pundit University, Thailand \\ ${ }^{3}$ Universiti Utara Malaysia, Malaysia \\ ${ }^{1}$ apichaya.nim@dpu.ac.th; ${ }^{2}$ worapat.png@dpu.ac.th; \\ ${ }^{3}$ chareen@uum.edu.my
}

\begin{abstract}
Current m-learning media are available in both native application and web-based application forms which create different user experience. Also, as the learners generally have diverse preferences and needs, a single style of m-learning may not meet such requirements. In order to formulate better and more attractive interaction between the learner and m-learning system, this study introduces augmented reality (AR) to both native and web applications as a means to improve captivation and create new user experience. A single group of learners is selected to try both types of application. The researcher groups the learner by learning style, using Felder-Silverman Learning Style Model, and then determines effectiveness of both forms of m-learning through an experiment. Experiment showed that all 4 learner groups were more satisfied with AR-enhanced native application based on user experience design due to its attractiveness and entertainment.
\end{abstract}

Keywords: AR-based native apps, augmented reality, mobile learning, user experience

\section{Introduction}

The increasing popularity and widespread use of m-learning today, along with more advanced mobile devices, contribute to diversity of learning media which was unseen in the past. Mobile devices, especially mobile phones, now become adequately powerful for new technology and presentation. m-Learning as a concept originated almost a decade ago but only saw rapid introduction in the last few years. Today, $\mathrm{m}-$ learning is used by $47 \%$ of organizations around the world, suggesting more acceptance of m-learning [1]. m-learning of today is developed as applications, which can be divided into 2 types namely, native app and web-based app. Native app directly utilizes all systems in the mobile device (such as camera and GPS) to their full capabilities, but the user has to download and install the application. The second type is web-based application, which can be accessed through mobile browser and the Internet. The Web-based application is more convenient but do not have full features of the native app. As a result, development of web-based learning media has more limitations in features.

Different strength and weakness of both systems result in the different user experience (UX). As native app has access to mobile phone features, diverse learning media can be developed. One method is mixing the reality with the virtual world by means of software and connected devices. This method is called "augmented reality" which sees the use of mobile phone camera in conjunction with m-learning to display content in many forms such as 2D and 3D image, information, audio and vid- 
eo. The use of this technology will grant the user new user experience, more interaction with the M-lesson and more interesting content. Conversely, the web application can display on the normal mobile browser, has less system requirements, higher accessibility and simpler learning curve (as most learners are already familiar with surfing the Internet on mobile phone) without the need to download and install the application.

Nevertheless, the same group of learners might be interested in the UX of different m-learning due to the learner's own learning style. In order to tailor learning media to the learner's preference, a survey is required to collect information on learning styles at individual level. The researcher categorizes learning style in accordance with Felder-Silverman learning style model. From the survey, the researcher is able to categorize the learner into four groups: visual learner, active learner, sensing learner and sequential learner. Each learner group has different interest, and mobile app UX and some might prefer one type of application over the other. Hence a guideline for m-learning, UX, and learning media development is necessary to tailor them to the user's needs in order to improve learning achievement and user engagement.

An augmented reality-enhanced which is native m-learning application was developed in this study to improve its attractiveness, create a new form of lesson interaction and provide new user experience. A web-based application which can be used on mobile devices was also developed to compare with the native application in terms of performance. An experiment is performed on learners with different learning styles to determine their preferred applications and how new user experience improves appeal and learning achievement.

\section{Literature Review}

\section{Mobile-Learning}

This term normally refers to learning on mobile devices especially mobile phones. In m-learning, the learner may participate in a learning activity with no limitations on time and place. Additionally, as the use of mobile devices increases and more advancements in mobile technology are attained, m-learning gains more popularity in education due to its accessibility, easy data transfer and compatibility with more diverse multimedia.

Although m-learning is merely the use of mobile devices to access learning content and information source, it has to be mindful that m-learning also includes the limitless unofficial learning instead of official courses. Jason Haag mentioned that Mlearning could be used for out-of-classroom learning [2]. McQuiggan proposed a view on M-learning that the learner is not only the recipient but an active part in the learning process, and accordingly must use its own ability to achieve the goal and improve the higher thought process [3].It is notable that features and benefits of $\mathrm{m}$ learning are suitable for the current technology and learner behavior and thus we must be more attentive of m-learning development suitable for the learner and the device.

\section{User Experience (UX)}

User experience usually originates from the use of anything and could either be positive or negative. Positive user experience will keep the user engaged. For this reason, we could call UX part of human-computer interaction and a crucial element to success of mobile app. Roto et al. stated that UX became a useful extension to the traditional HCI design as specified in the latest entrepreneur discussion [4]. Furthermore, Don Norman mentioned UX design as a multidimensional phenomenon that 
was influential to success, and more importantly, separated from user interface (UI) although UI already being an obvious factor in design [5].

The first generation of UX could be in 2000-2006 where UX is a concept on development process to ensure positive experience for a website. The second generation of m-learning application development focused on feature, user satisfaction, performance and efficiency. Main changes in this generation included change of focus from pure feature to human-application interaction and usability. Also, this generation saw the larger number of increasingly complex applications with use monitoring as a means to overcome challenges [6,7]. In the second generation, Seong defined $\mathrm{m}-$ learning application usability assessment in three categories namely, user interface, interaction and design [8]. The third generation of mobile phone UX was deemed the age of experience defining UX as "personal awareness and response arising from the use of product, system or service" [2]. Nielsen \& Norman defined m-learning as "human response and emotion as UX". In this age, developers are determined to pay more attention to user emotion so the user remains engaged [5,9]. As mentioned, user experience is developed in response to the user's use and needs. Later generations also focus on user emotion, which is important for user engagement.

\section{Native apps}

Native app is a mobile application specifically developed for mobile device and possibly OS (Operating System)-specific. Currently there are three most common OS in use, namely Android by Google, iOS by Apple and Windows by Microsoft. The advantage of this kind of application is its ability to use all phone features such as mobile camera, fingerprint scan, microphone or Global Positioning System (GPS), which result in more variety in m-learning lessons and features. Limitations of native applications include lack of cross-platform capability. William Jobe developed a native and web-based application in Slum run and found that native application worked well in jogging route tracking (due to ability to use GPS system on the phone), while web-based application worked well for hotel room booking (due to accessibility and low system requirements) but the latter is poorly-suited for route tracking due to slow GPS connectivity [10]. In addition, Kirusnapillai Selvarajah opined on native app as able to use existing features on the operating system, having interesting user interface and able to work offline. If Internet connection is required, the user is able to connect to the server (for file uploading, for example), while other parts of the application can continue as stand-alone features [11].

Studies on native application revealed that this kind of application allows more diversified learning media through various features on the mobile device, allowing more user interaction and more interesting courses.

\section{Web apps}

Development of web-based application is popular due to easier server-side management without the need for software distribution and installation on the client's part. However, web-based application does not have full access to phone features like native app. The advantage of web-based application is simple learning curve: the user does not need to learn how to use it, and lower system requirements. URL of the application can also be easily disseminated to other persons. Kirusnapillai Selvarajah opined on feature of web application as able to be accessed on mobile web browser and developed using JavaScript, HTML5 and CSS3 which allowed easy personalization. For the reasons mentioned, web-based application development cost tends to 
differ from one app to another. It also has cross-platform capability but less security due to constant connection to the server (vulnerable to attacks) [11].

However, decision to build native or web-based application depends on factors other than technical specifications and functional requirements, such as budget, resource and time limitation. In some cases, web application might be the best choice, depending on functionality.

\section{Augmented Reality (AR)}

Augmented Reality (AR) is a technology that blends the reality and the virtual reality (VR) by means of software and connected devices. AR can be classified as creation of virtual world components such as video, audio, 3D shapes and messages on reallife camera feed. Aside from being the mix between the real and virtual world, AR has instantaneous response. Regarding learning UX, AR is able to expand on UX improvement by using natural abilities. In addition, AR is a new kind of user interface that interacts with different types of data, which could be used to improve learning experience. Marc Ericson C. Santos mentioned that AR is a creation of a new learning experience for the user due to its unique characteristics. The use of AR is based on three theories: multimedia learning theory, experiential learning theory and animate vision theory.

The real world and visualization enable tangible interaction and more freedom in information searching. Implementation of AR technology can change UX, create new learning experience leads and finally better learning achievement [12]. Elizabeth FitzGerald mentioned that the learner's interaction with AR might be affected by the surrounding environment, group-work might be enhanced with $\mathrm{AR}$, and new learning styles can be created [13].

Nevertheless, AR still has its own limitations such as capability of the mobile device and Internet connection as prioritized by Davies et al. because AR might be sensitive to signal quality [14]. The researcher viewed that the use of AR technology in m-learning should take factors like learner type, mobile device, usage behavior and location.

\section{Learning style}

Physical characteristics, thought and feeling the person used to perceive, respond and interact with the learning environment are static, therefore thought and learning style are usual habits of an individual person. However, they are not capability per se, but rather how the person uses his or her own ability to think and learn. On relationship between thought and learning styles, and concept of development of thought process from individual interest and difference, this study would refer to Felder- Silverman Learning Style Model as a learning model for science student, to divide learning into active and reflective learner, sensing and intuitive learner, visual and verbal learner and sequential and global learner [15]. There are many books on learning styles in psychology and education. This adaptive mode may be more beneficial to learners than to the use of domain knowledge alone. Learning styles enable learners to learn effectively and be familiar with their capabilities [16,17].

However, while m-learning has impact on learner change, Hossein Movafegh Ghadirli gave importance on consideration of the current learning environment, and learning style as another factor in learning achievement improvement [18]. Thus we should take many factors in consideration in order to develop learning media for learners with different learning styles. There are many books on learning styles in psychology and education. 


\section{Research Methodology}

\section{Experimental Design}

This study aims to examine and experiment on comparison between m-Learning UX for native application with Augmented Reality to increase attractiveness, and web-based application to determine the most suitable application type for the learner. In this experiment, we used 140 freshman undergraduates aged between 18-20 years.

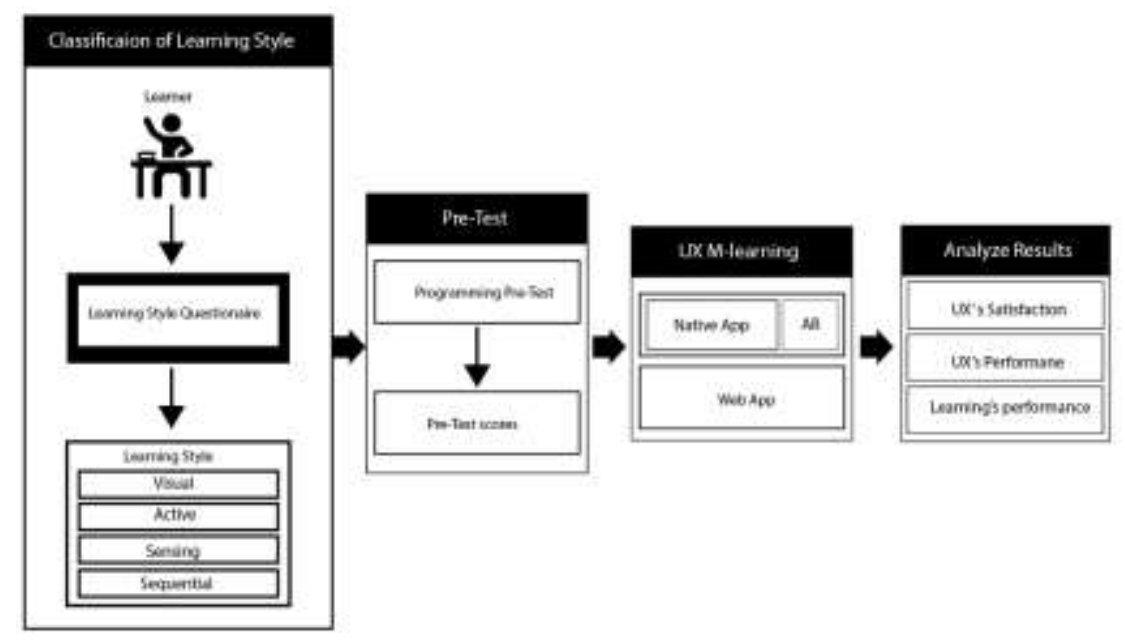

Figure 1. The framework for UX m-learning Intregrated Augmented Reality vs. Web App.

The first part of this experiment was a survey to collect data on learning style at individual level. The researcher used Felder-Silverman Learning Style Model to categorize learning styles into four types: active learner, sensing learner, visual learner and sequential learner. After the survey, the students were given a pre-test (in this experiment was a programming course test) to obtain the pre-test score before taking the class. Then, the researcher developed two m-learning courses, one as an AR-based native application and the other as a web application. The students were allowed to take both courses and take a post-test and an m-learning UX satisfaction evaluation form. Pre-test and Post-test scores were then compared and summarized to determine the most satisfactory m-learning style. This can be seen in Figure 1.

\section{Development of m-learning UX based on application type.}

There were two mobile application prototypes developed, one as a native application enhanced by AR (using the phone camera to scan AR code included in the lesson), and the second as a web-based application that is a responsive website accessible through mobile browser. The web-based application can be accessed by all types of mobile device. 

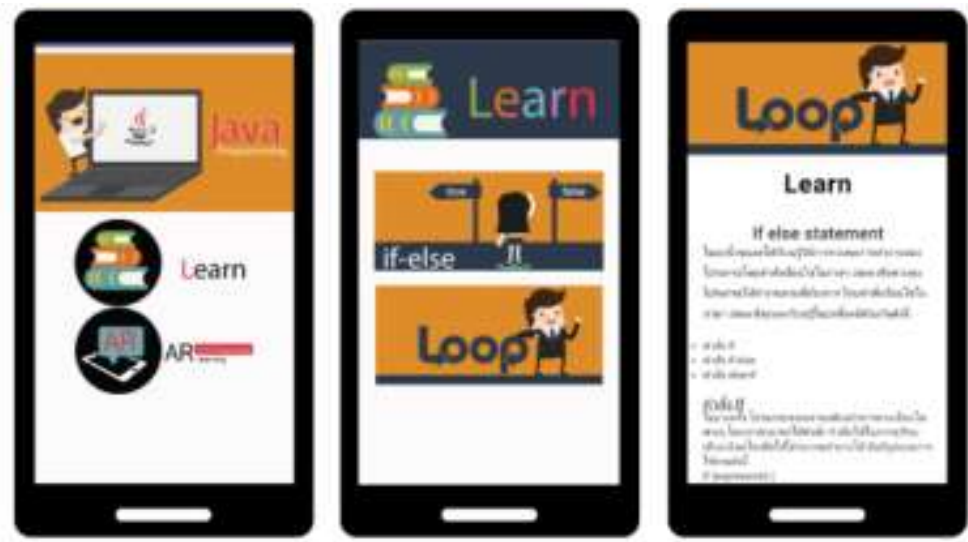

Figure 2. Native Application for Programming Course.

Figure 2 shows the AR-enhanced native application for programming course. The learner is required to download the application into the phone prior to use. The application has lessons and AR-based learning part where the student can scan the AR code on the supplementary document to access the AR course and exercise.
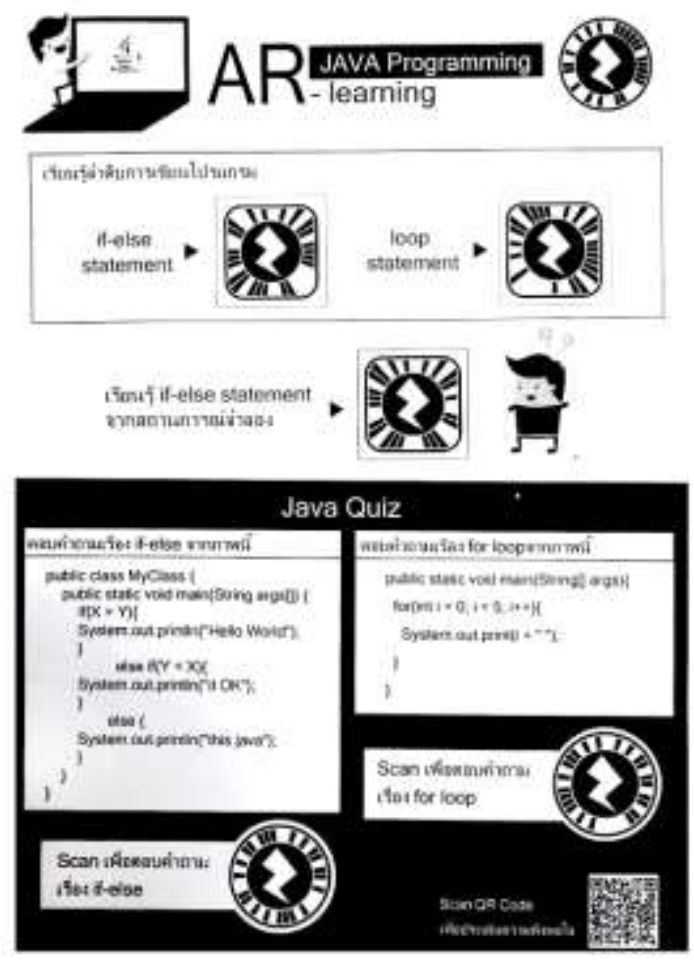

Figure 3. Supplementary document for the native application.

Figure 3 shows the supplementary document for the programming course. The student could access the AR feature by scanning AR code in the document with the application. There are animated and graphic media and interactive systems if the answer is right or wrong. 


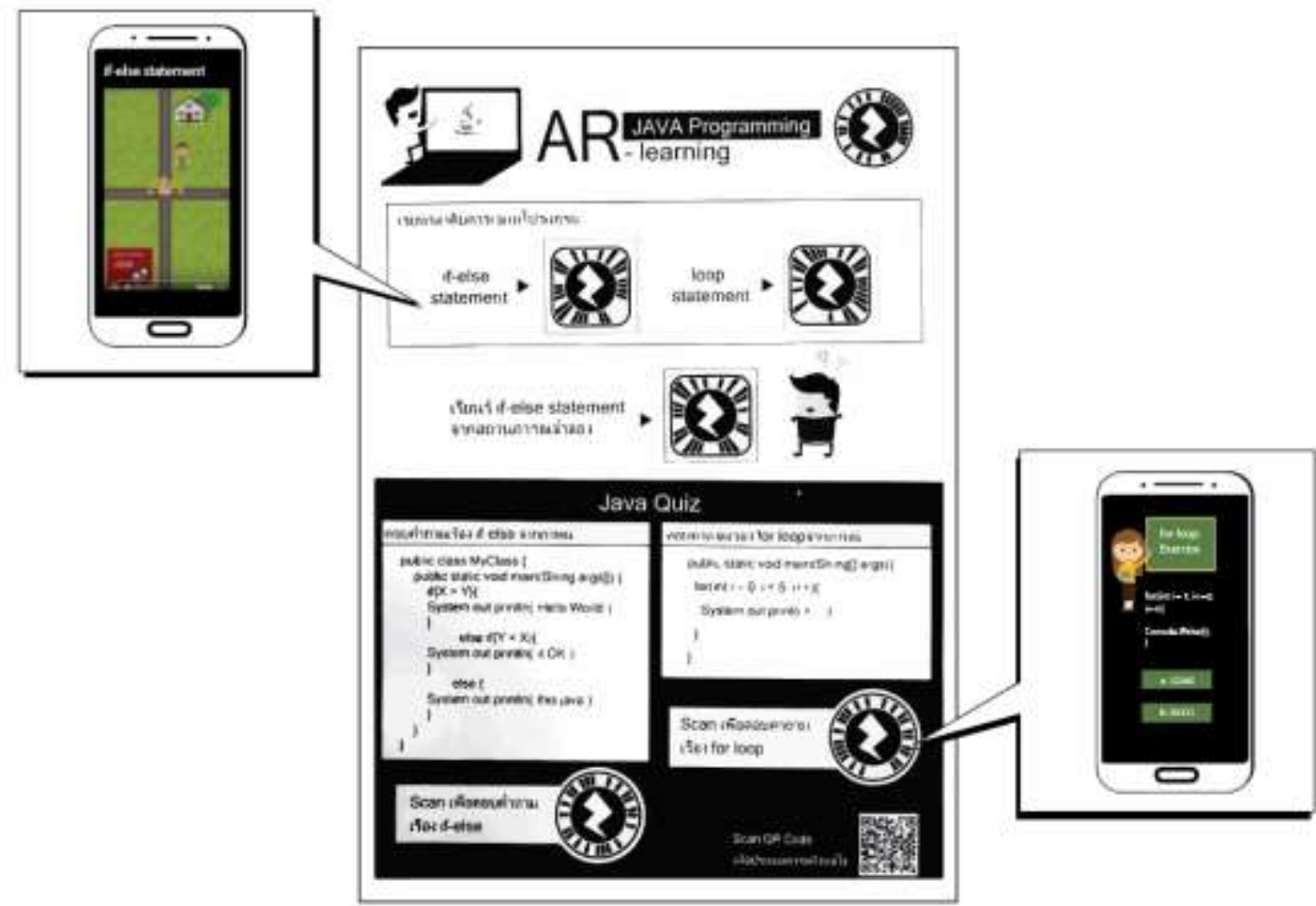

Figure 4. AR code scanning with the application.
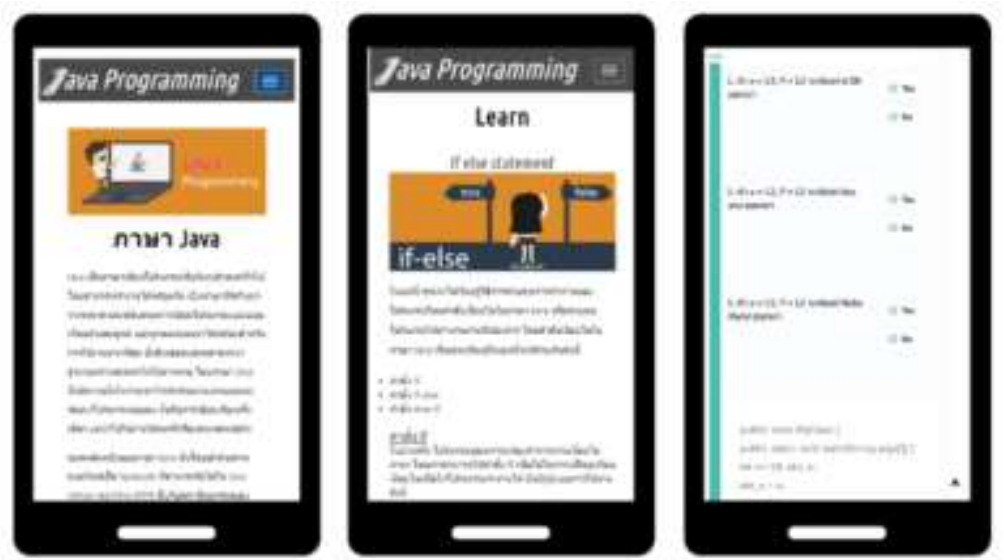

Figure 5. Web application for the programming course.

Aside from the native application as shown in Figure 2, the researcher also developed a web-based application for the student as shown in Figure 5. 


\section{Experimental Results}

\section{Summary of M-Learning UX from AR-Enhanced Application and Web-Based Application (By Satisfaction and Efficiency)}

Table 1.

Summary of User Satisfaction in Native and Web Applications.

\begin{tabular}{|c|c|c|}
\hline Factor & Native App & Web App \\
\hline Lesson attractiveness & 4.01 & 3.67 \\
\hline $\begin{array}{c}\text { Assistance in course under- } \\
\text { standing }\end{array}$ & 3.78 & 3.75 \\
\hline Entertainment & 4.15 & 3.66 \\
\hline Satisfying the learner needs & 3.86 & 3.74 \\
\hline User rating & 3.7 & 3.78 \\
\hline
\end{tabular}

Table 1 showed user satisfaction in both m-learning applications. Based on the table, most students are more satisfied with the native application due to its AR technology, which offers interactivity and attractiveness.

However, majority (slight majority at 0.08 points) of the learners prefer the web-based application over the native counterpart. Interview showed that most learners prefer web-based application as the native counterpart required an installation, which used up space (problematic for learners with limitations on phone performance and space) and time. Conversely, web applications can be accessed by convenient URL links and do not waste space on mobile applications.

From the summary, in addition to performance, download speed and file size, applications should take into account the loading speed and file size of the application.

Table 2.

Summary on Native and Web Application Performance.

\begin{tabular}{|l|c|c|}
\hline Performance & Native App & Web App \\
\hline Ease of use & 3.77 & 3.92 \\
\hline Lesson accessibility & 3.86 & 3.87 \\
\hline Downloading efficiency & 3.73 & 3.73 \\
\hline
\end{tabular}

Table 2 shows that in terms of performance, most learners praised ease of use and lesson accessibility of the web application, due to it being similar to normal web surfing. Downloading efficiency was rated equally as nowadays the mobile internet becomes powerful with $\mathrm{Wi}-\mathrm{Fi}$ and cellular options, which result in negligible difference between both application types. 


\section{Summary of M-Learning UX on AR-Enhanced Native Application Performance Related to the Traditional Method (Categorized by Learner Style)}

Table 3.

M-Learning Achievement Based on Learning Style.

\begin{tabular}{|c|c|c|c|c|}
\hline & Sequential & Active & Sensing & Visual \\
\hline Pre-Test & 6.04 & 2.89 & 4.32 & 5.23 \\
\hline $\begin{array}{c}\text { Post-Test (m-learning based on } \\
\text { Learning style) }\end{array}$ & 8.3 & 8.6 & 8.1 & 7.01 \\
\hline Incremental Percent & $37.42 \%$ & $197.58 \%$ & $87.50 \%$ & $34.03 \%$ \\
\hline
\end{tabular}

Table 4.

UX M-Learning Achievement (AR-Enhanced Native Application).

\begin{tabular}{|c|c|c|c|c|}
\hline & Sequential & Active & Sensing & Visual \\
\hline Pre-Test & 6.04 & 2.89 & 4.32 & 5.23 \\
\hline $\begin{array}{c}\text { Post-Test (AR-enhanced native } \\
\text { application) }\end{array}$ & 7.05 & 7.52 & 8.57 & 7.67 \\
\hline Incremental Percent & $16.72 \%$ & $160.21 \%$ & $98.38 \%$ & $46.65 \%$ \\
\hline
\end{tabular}

From Table 3, all four types of learners had increased learning achievement after the UX m-learning with learning materials tailored to learner styles. Also, there were increases in learning achievement when exposing the learners to AR-enhanced UX m-learning native application as seen on Table 4. Although all groups showed improvement, sensing and visual groups showed larger improvement than with the traditional media, because the sensing group learned by practice and preferred connection to the real world, and the visual group preferred visual information in the form of animation, flowchart, or video, especially with voiceover. Both groups were interested in the AR-enhanced native application and when scanning AR Code, students will be able to see the lesson in the form of animation video and interactive. It can be used to answer questions. This may be the reason why both types of learners have increased learning outcomes.

\section{Conclusion}

Currently there are 2 types of m-learning: native application and web application, each formulating its own unique user experience. Also, learners have diverse learning styles and preferences. In this study, the researcher divided learners into 4 types based on Felder-Silverman Learning Style Model: sequential, sensing, visual and active. As a result, neither form of m-learning is able to satisfy all learners. In order to create a new, more interesting learner-system interaction, the researcher developed an augmented reality-based native application to better integrate virtual world with the real world, in addition to a web-based application which offered high accessibility through mobile devices. All 4 learners groups tested both applications to determine their satisfaction and found that all 4 groups were more satisfied with the AR-based native application due to its new user experience being more attractive and 
entertaining, resulting in good impression and user engagement. Learning achievement of all 4 groups were found to be increased especially sensing and visual groups, signifying usefulness of augmented reality in user experience development.

However, one interesting issue is preference of web application over native application with only 0.08 point of difference in rating. As the sample group consisted of students, some had phones that were inadequate for the relatively resourceintensive native application. This issue prevented full embrace of the native application. In the future, the researcher will examine other factors and technology that could be implemented in UX m-learning development, to create more diverse m-learning media which can further improve learning achievement.

\section{CONFLICT OF INTERESTS.}

\section{There are non-conflicts of interest .}

\section{References}

[1] Ashapandey, "10 Mobile Learning Trends For 2018", 2018. Available: https://elearning.adobe.com/2018/05/10- mobile-learning-trends-2018/.[Accessed: May 10,2018]

[2] H. Jason, "ISO 9241 Part 210: Human-centred design for interactive systems, in ISO 9241 Ergonomics of human system interaction, 2010," eLearning to mLearning: The Effectiveness of Mobile Course Delivery, Interservice/Industry Training, Simulation, and Education Conference (I/ITSEC) 2011. Paper No. 11053 Page 1-13, 2010. Available: https://www.iso.org/standard/52075.html. [Accessed: March 2013]

[3] S. McQuiggan, J. McQuiggan, L. Kosturko, and J. Sabourin, Mobile Learning: A Handbook for Developers, Editors and Learners. North Caroline: SAS Institute Inc., 2015.

[4] User Experience White Paper, "Bringing clarity to the concept of user experience Result from Dagstuhl Seminar on Demarcating User Experience", 15-18 September 2010

[5] N. Don, World Leaders in Research-Based User Experience :The Definition of User Experience $\quad 2017 . \quad$ Available: https://www.nngroup.com/articles/definition-user-experience/ [Accessed: May 15, 2018].

[6] J. J. Garrett, The Elements of User Experience: User-Centered Design for the Web, Peachpit Press, 2000.

[7] V. Roto,"Web Browsing On Mobile Phones - Characteristics Of User Experience," Dissertation . Department of Computer Science and Engineering, Helsinki University of Technology (Espoo, Finland), 2006.

[8] D. S. K. Seong, "Usability Guidelines for Designing Mobile Learning Portals," In ACM International Conference Proceeding, Proceeding 3rd International Conference Mobile Technology Application System, 2006, vol. 270, pp: 1-8.

[9] J. Nielsen and D. Norman “The Definition of User Experience," NNG articles, World Leaders in Research-Based User Experience, 2015. Available: 
https://www.nngroup.com/articles/definition-user-experience/. [Accessed: May $15,2018]$.

[10] J. William, "Native Apps vs. Mobile Web Apps," International Journal of Interactive Mobile Technologies (iJIM), vol. 7, no. 4, 2013. Available: http://dx.doi.org/10.3991/ijim.v7i4.3226. [Accessed: May,20 2018].

[11] S. Kirusnapillai and P. C. Michael, "Native Apps versus Web Apps: Which is Best for Healthcare Applications?," M. Kurosu (Ed.): Human-Computer Interaction, Part II, HCII 2013, LNCS8005, 2013, pp.189-196.

[12] M. E. C. Santos, and A. Chen, "Augmented Reality Learning Experiences: Survey of Prototype Design and Evaluation," IEEE Transactions On Learning Technologies, vol.7, no.1, 2014.

[13] E. FitzGerald and R. Ferguson, "Augmented Reality and Mobile Learning : The State of the Art," International Journal of Mobile and Blended Learning, vol. 5, no. 4, pp. 43-58, 2013.

[14] S. J. Davies, T. Collins, M. Gaved, J. Bartlett, C. Valentine, and L. McCann, "Enabling remote activity using mobile technology for remote participation in geoscience fieldwork," presented at EGU General Assembly, Vienna, Austria, 2010.

[15] R. M. Felder, and L. K. Silverman, "Learning styles and teaching styles in engineering education," Engineering Education, vol. 78, pp. 674-681, 1988.

[16] E. Brown, T. J. Brailsford, T. Fisher and A. Moore, "Evaluating learning style personalization in adaptive systems: Quantitative methods and approaches," IEEE Transactions on Learning Technologies, vol. 4, no. 1, pp. 5-20, 2011.

[17] K. A. Papanikolaou, A. Mabbott, S. Bull and M. Grigoriadou, "Designing learner-controlled educational interactions based on learning/cognitive style and learner behavior," Interacting with Computers, vol. 18, no. 3, pp. 356-84, 2006.

[18] H. M. Ghadirli, and M. Rastgarpour, "Effectiveness of Learning Style in Popularity of Personalized Mobile Intelligent Tutoring System from View of Learners," Indian Journal of Science and Technology, vol. 9, no. 31, pp.1-8 , 2016. 